\title{
DIVISÃO SEXUAL DO TRABALHO E DIVERSIDADE LINGUÍSTICA NA SUBALTERNIZAÇÃO DAS INFÂNCIAS: OPRESSÕES ÉTNICAS, LINGUÍSTICAS E CULTURAIS NA REPRODUÇÃO DAS DESIGUALDADES Sexual division of labor and linguistic diversity in the subalternization of childhoods: ethnic, linguistic and cultural oppressions in the reproduction of inequalities
}

\author{
Adriana Alves da SILVA \\ Departamento de Pedagogia/DPED \\ Universidade do Estado de Santa Catarina \\ Florianópolis, Brasil \\ silvadida07@gmail.com \\ https://orcid.org/0000-0002-1407-783X
}

Rosali Rauta SILLER

Departamento de Teorias de Ensino e Práticas Educacionais do Centro de Educação Universidade Federal do Espírito Santo Vitória-ES, Brasil rauta13@gmail.com https://orcid.org/0000-0002-5296-8908 이

Vanderlete Pereira da SILVA

Escola Normal Superior Universidade do Estado do Amazonas Manaus-AM, Brasil

vpsilva@uea.edu.br

https://orcid.org/0000-0001-9353-3110 (])

\section{RESUMO}

O artigo, a partir de uma pesquisa documental, analisa opressões étnicas, linguísticas e culturais que operam simultaneamente, focando nas crianças pomeranas e manauaras em condições de desigualdades, investigando nos documentos que orientam as políticas públicas para a Educação Infantil. Buscamos explicitar um sistema que atua para homogeneizar as infâncias, negando e excluindo as diferenças e questionamos: para que e por que propor um único programa de leitura e escrita na Educação Infantil num país com 274 diferentes línguas faladas? Na articulação da diversidade linguística com a divisão sexual do trabalho, evidenciando a indissociabilidade do cuidado e da educação de filhas e filhas pequenas/os, visamos contribuir na construção de uma Pedagogia descolonizadora, apontando neste percurso desafios das políticas públicas para a Educação Infantil brasileira.

PALAVRAS-ChAVE: Educação Infantil. Divisão sexual do trabalho. Diversidade linguística.

\begin{abstract}
The paper is based on documentary research and analyzes ethnic, linguistic and cultural oppressions that operate simultaneously. It focuses on Pomeranian and Manauarian children under conditions of inequality and investigates documents that guide public policies for Early Childhood Education. We sought to clarify a system that acts to homogenize childhoods, denying and excluding differences and we question: for which reason and why proposing a single reading and writing program in Early Childhood Education in a country with 274 different languages spoken? In the articulation of linguistic diversity with the sexual division of labor, highlighting the inseparability of the care and education of young sons and daughters, we aim to contribute in the construction of a decolonizing pedagogy, pointing out challenges of public policies for Brazilian early childhood education in this path.
\end{abstract}

KEYWORDS: Early childhood education. Sexual division of labor. Linguistic diversity. 


\section{INTRODUÇÃO}

Por sua vasta gama de contextos e de suas dimensões continentais, o Brasil não é, como erroneamente se supõe, um país homogêneo, que tem como padrão uma identidade nacional referenciada a um povo, uma raça, um grupo étnico, uma cultura, uma religião, um território, tampouco se fala somente o português. Coexiste no país uma variedade de grupos étnicos e linguísticos, os quais, muitas vezes, coabitam uma mesma região, com suas diferentes línguas, formas de ser, viver, conviver e dançar que Ihes são próprias.

Caracterizado por uma história de migrações, marcado pela tradição de receber imigrantes de todas as partes do mundo e pelos deslocamentos internos de pessoas que se movimentam de regiões consideradas de menos condições de sustentabilidade a outras de maior projeção econômica, o Brasil é considerado um país das migrações. Essa história tem início com os europeus, atraídos pela política de colonização. Inicialmente (século XVI), chegam os portugueses para "colonizarem as terras que pertenciam aos indígenas" (GARCIA, 2015); posteriormente, no processo de invasão e disputa territorial, trouxeram negros/as africanos/as para constituir a mão de obra escrava em nosso país. De acordo com Darcy Ribeiro (1995), aos cinco milhões de índigenas que habitavam o Brasil, no ano de 1500, chegaram mais outros cinco milhões de europeus, seis milhões de pessoas oriundas da África, forçadas a trabalhar como escravos (RIBEIRO, 1995 apud MEGALE, 2014).

$\mathrm{E}$, mais tarde, antes mesmo da Independência, em meados do século XIX (entre o período de 1808 a 1859), chegou um número elevado de imigrantes, que se dirigem às regiões Sul e Sudeste e formam os primeiros núcleos coloniais, na tradição da pequena propriedade rural e da agricultura familiar. Esses fluxos migratórios foram formados pelos suíços e outros grupos oriundos de várias províncias da então Confederação Alemã - Reno, Hunsrück, Hesse, Bavaros, Treves, Prússia, Pomerânia, italianos, tiroleses, austríacos, luxemburgueses, holandeses badeneses (DIEGUES, 1964, BAHIA, 2015). Além da imigração nesse mesmo período e início do século XX, grandes contingentes imigratórios chegavam principalmente para as cidades, atraídos pelo desenvolvimento urbano e pelo crescimento industrial (DIEGUES, 1964), dentre os quais destacamos: italianos, japoneses, libaneses, poloneses, espanhóis, chineses, coreanos. Salientando que nesses movimentos de imigração internacional as crianças sempre estiveram presentes. 
No início do século XXI, em menor proporção, o Brasil volta a ser um país de atração de novos imigrantes de diferentes partes do mundo, em especial da América Latina. Desses imigrantes, "cerca de 40\% deles são de países da América do SulArgentina, Chile, Bolívia, Paraguai, Peru e Uruguai-; mais de 20\% da Europa; 12,5\% da Ásia e 9,1\% da América do Norte" (PATARRA, 2005, apud NASCIMENTO \& MORAIS, 2020, p.443). Além da "imigração forçada" (BEZERRA, 2016) de refugiados de diversas nacionalidades, que chegam com suas crianças, fugindo de conflitos armados. Dentre esses imigrantes estão os sírios, haitianos, angolanos, colombianos, congoleses, palestinos, venezuelanos, cubanos, chineses, bengaleses (BEZERRA, 2016; ASSUMPÇÃO, 2019).

Não obstante, essa movimentação de crianças não está centrada, exclusivamente, na imigração internacional, pois internamente há também uma intensa "andança nacional" (MARTINS, 1991). Os primeiros brasileiros a vivenciarem os deslocamentos internos foram os indígenas que, retirados de suas terras, foram levados à força para outros espaços, principalmente para trabalharem na agricultura. Aqueles que fugiam para o interior foram escravizados para plantar na terra que há pouco tempo era sua. E, assim, outros deslocamentos foram se dando em nosso país, dos "campos para as cidades, das cidades para os campos, dos campos para os campos, das fronteiras para o centro, do centro para as fronteiras, do Nordeste para o Sudeste, do Sul para o Centro-Oeste e para o Norte, do Centro Oeste e do Norte para o Sul" (BANETTI; VAINER, 1988, p. 8).

Em maior ou menor escala, os grupos trouxeram milhares de crianças para o país (DEMARTINI, 2006; GOES \& FLORENTINO, 2007; KOHLRAUSCH, 2006). Acompanhadas por suas famílias, as crianças participaram desses movimentos de migrações internacionais e internas, não por escolha, mas em função da necessidade e/ou desejo de suas famílias em buscar um país que julgavam ser melhor e com mais oportunidades (ASSUMPÇÃO, 2019). Elas trouxeram línguas, culturas, saberes e fazeres dos seus territórios de origem.

Há, portanto, nos diferentes contextos brasileiros, cerca de "pelo menos 170 línguas indígenas, 30 línguas de imigrantes, duas línguas de sinais (língua brasileira de sinais-Libras - e a língua dos Urubu-Kaapor) e, evidentemente, a língua portuguesa" (MAHER, 1977, p. 22), as línguas de regiões de fronteiras, além daquelas trazidas por imigrantes refugiadas/os, desafiando a crença da unidade cultural e linguística do país e desconstruindo o mito do "monoculturalismo" e do "monolinguismo". Embora 
considerada constitucionalmente ${ }^{1}$ língua oficial da União, ainda assim a língua portuguesa não é a língua materna de muitos grupos étnico-culturais e tampouco a única falada em nosso país. Retiradas de seus locais de origem, essas crianças, parafraseando Ailton Krenak (2019, p. 09), foram e continuam sendo "jogadas neste liquidificador chamado humanidade" E, em suas novas localidades, cotidianamente, são incitadas a se afastarem de suas línguas e de outras especificidades que as diferenciam e a se apresentarem como sujeitos homogêneos.

\section{ARTICULAÇÕES EMERGENTES: INFÂNCIAS SUBALTERNAS, DIVISÃO SEXUAL DO TRABALHO E DIVERSIDADE LINGUÍSTICA}

Frente a esses contextos, tomar a criança e a infância de modo universal, como sujeito homogêneo, em sua negatividade, é um equívoco. Trata-se de uma metáfora, de uma invenção da modernidade, que pretende "naturalizar", padronizar, normalizar e subalternizar essas crianças que fogem à regra de um modelo hegemônico de supremacia branca, de origem europeia de classes sociais mais abastadas, famílias consanguíneas, heteropatriarcal, de origem territorial urbana, de idioma português. As crianças que não se enquadram nesse modelo são subalternizadas e inferiorizadas. Elas não são ouvidas, e os seus jeitos de falar, de agir, de ser, de viver, de conviver, de dançar, que Ihes são próprios, sofrem as opressões históricas e as múltiplas desigualdades desse projeto civilizatório.

Dentre tantas crianças subalternizadas, neste texto, a partir das nossas pesquisas (SILLER, 1999, 2011; SILVA, 2020), buscamos dar visibilidade às crianças pomeranas e manauaras. As crianças pomeranas, do município de Santa Maria Jetibá, localizado na região Centro-serrana do estado do Espírito Santo, com uma população residente de 39.356 pessoas, das quais 25.797 residem no meio rural $(65,55 \%)$ e 13,559 (34,45\%), no meio urbano (IBGE, 2016). Município originário do século XIX, com a chegada, em 1859, dos primeiros pomeranos, provenientes da Pomerânia². São

\footnotetext{
${ }^{1}$ A língua portuguesa é instituída como língua oficial da União, conforme artigo 13 da Constituição Federal de 1988.

2 A antiga Pomerânia, território subdividido em Vorpommern (Pomerânia Ocidental ou Anterior) e Hinterpommern (Pomerânia Oriental ou Posterior). Da Pomerânia Oriental vieram os primeiros pomeranos para o Espírito Santo, sendo a maioria deles empobrecidos e desprovidos da propriedade da terra. Em 1817, a Pomerânia tornou-se uma província da Prússia. O Reino da Prússia foi um Estado independente entre 1701 e 1871, quando uniu os estados teutônicos sob seu domínio (Guerra Franco-Prussiana), criando o Império Alemão (1871). Com a derrota da Alemanha na Segunda Guerra Mundial (1945), a Pomerânia Oriental é anexada à Polônia e a Pomerânia Ocidental passa a integrar o atual Estado de MecklenburgoPomerânia Ocidental, Alemanha. No final da Guerra, a população pomerana foi expulsa pelo Exército Vermelho e teve de deixar, às pressas, a sua terra natal; a grande maioria fixou residência na Alemanha,
} 
filhas e filhos de agricultoras/es familiares, camponesas/es pomeranas/os, que desenvolvem uma agricultura diversificada e distinta da monocultura dos grandes latifúndios, fazendo com que a agricultura familiar ${ }^{3}$ se apresente como uma de suas principais características. As formas de produção agrícola na pequena propriedade rural estão vinculadas ao respeito à biodiversidade, à produção para o mercado interno, à garantia da soberania alimentar e, principalmente, à valorização e preservação da língua pomerana; os saberes e fazeres ancestrais são centrais na vida dessas crianças e de suas famílias.

As crianças pomeranas da sexta geração são bilíngues, falantes da língua pomerana e da língua portuguesa, e há também aquelas crianças que chegam à instituições de Educação Infantil falando somente a sua língua materna, a língua pomerana (SILLER, 1999; 2011; 2020). Na vida cotidiana daquelas meninas pequenas e meninos pequenos pomeranas/os, nos lugares frequentados por elas/eles, além da casa e da pequena propriedade, nas igrejas luteranas era a língua materna a mais utilizada por essas crianças, principalmente porque seus avós, ou mesmo os pais/as mães entendiam melhor a língua pomerana.

Por meio da oralidade, pelo fato de a cultura pomerana ser ágrafa, os adultos, sobretudo as mulheres, assumem essa responsabilidade de apresentarem às crianças a língua pomerana e todo o legado de heranças simbólicas e materiais ancestrais. Como as crianças pomeranas passam a maior parte do tempo com as mulheres (mães, avós, irmãs mais velhas), envolvidas em uma vida intimamente vinculada à casa, à lavoura, à igreja e ao comércio local, nesse convívio aprendem desde muito cedo que existem atividades consideradas para mulheres e outras para homens.

Com as mulheres, além da língua pomerana, as crianças aprendem a cultivar a terra, e as meninas, em especial, vão aprendendo desde muito cedo a ajudar nos pequenos serviços domésticos, como o trato dos animais, na limpeza dos arredores da casa, no cuidado das crianças menores, além de observarem todo os serviços dos mais velhos. Os bebês, logo após o batismo, também são levados à propriedade e lá

\footnotetext{
e outros emigraram para os Estados Unidos e Austrália. Assim, a partir de 1945, a (antiga) Pomerânia não mais existe como unidade geográfica na Europa. No entanto, é importante salientar que o(a)s imigrantes pomerano(a)s chegaram ao Espírito Santo antes de a Alemanha tornar-se um estado-nação. Ver TRESSMANN, Ismael. Da sala de estar à de baile: estudo etnolinguístico de comunidades camponesas pomeranas do estado do Espírito Santo. Rio de Janeiro: Universidade Federal do Rio de Janeiro, 2005.

${ }^{3}$ A agricultura familiar é a constituída pelo trabalho familiar e pelo assalariamento temporário, por exemplo, nos períodos de safra. [...] é reconhecida pela sua produtividade (especialmente de alimentos), por suas iniciativas de reorganização do trabalho e da produção, através da cooperação, e por sua resistência histórica na sociedade moderna (FERNANDES; CERIOLI; CALDART, 2004, p.32-33).
} 
permanecem dentro de um caixote de madeira, feito pelo pai, para que possam ter as atenções da mãe enquanto trabalha na propriedade. Os homens, por outro lado, além desses espaços situados entre a propriedade, a família e a igreja, eles circulam nos comércios locais, estaduais e internacionais. São eles os responsáveis pelas compras no supermercado, pela compra dos suplementos agrícolas ou ração para os animais. Aos domingos, costumam ir à igreja com a família, e às vezes vão jogar bola ou assistirem a algum jogo de futebol, que acontece nas proximidades de suas residências.

A divisão sexual do trabalho e os papéis sociais de gênero são bem demarcados entre eles; salientamos que o conceito de divisão sexual do trabalho e as relações sociais de sexo (HIRATA; KERGOAT, 2009), que, historicamente, no sistema capitalista, estamos todos inseridos, produzem hierarquias, opressões, explorações e desigualdades. E nos incitam a problematizar o eixo do trabalho como central na reprodução da vida, articulando na questão das infâncias a invisibilidade do trabalho das mulheres, sobretudo nas relações imprescindíveis e indissociáveis de educação e cuidado.

Na cidade de Manaus, capital do Amazonas, estado onde vivem sessenta e seis povos indígenas, que falam cinquenta e três línguas (IBGE, 2010), as crianças que vivem e estudam em escolas da zona urbana e ribeirinha falam a língua portuguesa. Na Associação de Mulheres do Alto Rio Negro (AMARN), existente em Manaus desde a década de 1980, reúnem-se mulheres moradoras da cidade de Manaus, de onze etnias indígenas. Nas reuniões bimestrais que acontecem na Associação, as mulheres se comunicam na língua Tukano, falada pelo povo Tukano e por outras etnias também. Embora haja mulheres de outros povos que têm sua própria língua, algumas já não sabem mais falar e adotaram a língua Tukano para resguardar seu pertencimento étnico. Essas mulheres têm filhas e filhos que estudam nas escolas públicas de Manaus, crianças invisibilizadas, não havendo preocupação por parte do poder público de iniciativas que valorizem a preservação das línguas e da cultura dos povos da Amazônia.

Algumas mulheres não falam a língua do seu povo mesmo em casa com suas crianças, pois aprenderam desde cedo o quanto pode ser prejudicial para as/os filhas/os não ter o domínio da língua portuguesa. As mães querem proteger suas crianças do preconceito do qual a maioria delas foi vítima. As mulheres contam que, num passado não muito distante, seus antepassados viveram em missões religiosas, onde eram castigados para não falar suas línguas e aprenderem a língua portuguesa. Desde a 
invasão portuguesa, as crianças indígenas convivem com a violência na Amazônia, conforme destacam Ratusniak, Silva e Mafra (2020, p. 1365):

\begin{abstract}
As crianças sempre estiveram enredadas nas lutas e atrocidades cometidas contra os povos originários. Elas nunca foram protegidas da violência da invasão. Pelo contrário, quando não eram assassinadas, eram recrutadas para a catequização, conversão e dominação, camufladas sob o nome de educação, e obrigadas a abandonar sua língua, sua cultura e a se submeter aos modos de se viver impostos pelos colonizadores.
\end{abstract}

Os dados do IBGE de 2010 demonstram que, fora das terras indígenas, apenas $12,7 \%$ falam a língua indígena e 87,3\% não falam. No geral, 95,5\% dos povos indígenas falam a língua portuguesa e 3,5\% não falam. Os dados evidenciam o poder da colonização sobre os povos originários, agravado pelas reflexões de Fanon (2008, p. 34), quando afirma que: "o homem que possui a linguagem possui, em contrapartida, o mundo que essa linguagem expressa e que Ihe é implícito".

Diante desse contexto, somos mobilizadas a continuar perguntando: por que o Brasil não se autorreconhece multicultural, multilíngue?

O conhecimento hegemônico com bases eurocentradas, produzido e imposto no processo de dominação e expansão colonial, a partir de modelos universais e generalistas, não permitiu que os subalternizados pudessem falar em sua própria língua, e com isso manifestar suas culturas, seus saberes e fazeres ancestrais. Ao contrário, tentou colocar as/os colonizadas/os, subalternizadas/os dentro de uma moldura, impondo a língua, os valores, saberes e costumes em conformidade aos modos dominantes. "Se no contexto da produção colonial o sujeito subalterno não tem história e não pode falar" (SPIVAK, 2010, p. 67), entendemos que as crianças manauaras e pomeranas, sujeitos subalternizados deste estudo, que se diferenciam por aspectos econômicos, sociais, culturais, religiosos, linguísticos etc., encontram-se ainda mais silenciadas e no esquecimento.

Spivak (2010, p.13-14) faz uso do termo subalterno para se referir "às camadas mais baixas da sociedade constituída pelos modos específicos de exclusão dos mercados, de representação política e legal, e da possibilidade de se tornarem membros plenos no estrato social dominante". Sujeito subalterno é "aquele cuja voz não pode ser ouvida".

Em uma análise a "contrapelo" da historiografia, como propõe Walter Benjamin (1994), buscamos descortinar a origem das relações de indiferenciação, acobertamento, ocultamento das infâncias pomeranas e manauaras que contribuíram para legitimar desigualdades múltiplas. Nessa busca, conseguimos evidenciar fatores 
que agiram simultaneamente e impuseram a essas crianças a alternativa de se desprenderem de vínculos étnicos, linguísticos e culturais ancestrais.

Essas crianças, dentre tantas outras, foram acometidas pela imposição e opressão de uma onda de políticas nacionalistas e colonialistas, o que fez com que a xenofobia se tornasse uma prática comum, geradora de estigmas, estereótipos e preconceitos pela vinculação de origem étnica, de origem territorial, de uso da língua materna, desenvolvendo nelas um processo de desvalorização, um sentimento de inferioridade, com base na percepção de que elas são "estranhas", "estrangeiras" à sociedade brasileira tão diversa, tão plural. Vinculada ao projeto de dominação colonial arquitetado pelos europeus, que buscava impor um padrão de dominação de modelos universais e generalistas, a imposição da língua portuguesa contribuía para a homogeneização das várias infâncias.

Em relação às crianças manauaras de grupos de etnias indígenas as mais variadas e com uso de distintas línguas, a imposição da língua portuguesa se deu inicialmente por meio da Lei do "Diretório dos Índios", ou "Diretório Pombalino", documento jurídico criado em 1755 e divulgado em 1757, que perdurou por quarenta e três anos, revogado somente pela Carta Régia de 12 de maio de 1798. Alguns preceitos legais estabelecidos nesse documento "denotam a crença de que a utilização da língua portuguesa contribuía para a civilização dos índios, pois a "língua do Príncipe" seria a base da civilidade e deveria, portanto, ser ensinada" (OLIVEIRA; MESQUITA, 2019, p.6). Além de tornar obrigatório o uso da língua portuguesa, dentre tantos outros aspectos, essa lei desconsiderou a cultura dos diferentes povos indígenas que habitavam o território antes da chegada dos colonizadores, definindo o modo de como seria a educação de meninas e meninos, conforme expresso no parágrafo 70 do Documento:

[...] haverá em todas as Povoações duas escolas públicas, uma para meninos na qual se lhes ensine a Doutrina Cristã, a ler, escrever, e contar na forma, que se pratica em todas as Escolas das Nações Civilizadas e, outra para as Meninas, na qual, além de serem instruídas na Doutrina Cristã, se Ihes ensinará a ler, escrever, fiar, fazer renda, costurar, e todos os mais ministérios próprios daquele sexo (DIRETÓRIO, 1758, §7).

Maher (2013), em pesquisa realizada no estado do Acre, a respeito das línguas indígenas, aponta os efeitos devastadores dessa política colonizadora na língua e cultura indígena. Afirma a autora:

[...] embora a língua indígena seja falada por pessoas de todas as faixas etárias (adultos, jovens e criança), já se percebe um aumento no número de crianças que têm o português como língua materna. Além disso, também se observa 
um declínio no número de domínios comunicativos nos quais a língua indígena é confortavelmente utilizada: em algumas situações, os falantes parecem preferir se comunicar, entre si, em português, em parte porque o vocabulário da língua indígena não dá conta do que as pessoas querem ou precisam dizer (MAHER, 2013, p. 240).

Mais do que a utilização da língua portuguesa, prática comum em todas as Nações que conquistaram novos domínios, o que se pretendia era a assimilação da própria identidade portuguesa, à qual os nativos deveriam se adequar, conforme previa o parágrafo $6^{\circ}$ do Diretório.

[...] introduzir logo nos povos conquistados o seu próprio idioma, por ser indiscutível, que este é um dos meios mais eficazes para desterrar dos Povos rústicos a barbaridade dos seus antigos costumes, e ter mostrado a experiência, que ao mesmo passo, que se introduz neles o uso da Língua do Príncipe, que os conquistou, se Ihes radica também o afeto, a veneração, e a obediência ao mesmo Príncipe (DIRETÓRIO, § 6).

Em relação às crianças pomeranas, a supremacia ideológica da cultura alemã apresentou-se no cenário brasileiro desde o início da colonização, como superior às culturas de grupos de imigrantes tão heterogêneos, que viviam em seus núcleos coloniais segundo suas próprias culturas, língua, religião, formas de ser, de viver, dentre os quais situam-se os pomeranos. No processo de unificação da Alemanha, concretizado em 1871, no afã de ampliar continuamente o seu domínio político e econômico da nova nação, a população de ascendência germânica que vivia no Brasil tornou-se alvo dos interesses econômicos do capital alemão e práticas xenófobas foram instauradas. Para preservação do "germanismo", no sentido de colocar na "categoria de alemães", foram silenciando as especificidades de grupos de imigrantes tão heterogêneos, que saíram de suas terras antes mesmo da unificação da Alemanha. Estratégias foram utilizadas para limitá-los à condição de "alemães". Na língua alemã eram realizados os cultos e o catecismo para crianças, jovens, adultos, idosos que só falavam a língua pomerana. Também a Bíblia e os hinários eram editados em alemão. Enfim, o nacionalismo e o imperialismo capitalista da Alemanha puseram os pomeranos e vários povos germânicos diante da dura alternativa de se desprenderem de vínculos étnicos e linguístico-culturais ancestrais.

Essa política intensifica-se no contexto da Segunda Guerra Mundial, e esbarra-se aqui no Brasil com os postulados do nacionalismo do Governo Getúlio Vargas, período da ditadura do Estado Novo (1930-1945), baseados na necessidade de tornar o Estado homogêneo, uma língua, uma cultura, uma religião, para garantir a continuidade da ideia de constituição de uma nação. Tal "igualdade de tratamento" para as crianças 
que não são iguais tem contribuído para transformar a especificidade da diferença em deficiência (TURRA, 1990).

Mudanças na educação brasileira foram efetivadas por meio do Decreto Lei no 406, publicado no ano de 1938, no governo Getúlio Vargas, que afetaram diretamente as crianças pomeranas, conforme expresso em seus três primeiros artigos.

\footnotetext{
$\$ 1^{\circ}$. As escolas a que se refere este artigo serão sempre regidas por brasileiros natos.

$\$ 2^{\circ}$. Nelas não se ensinará idioma estrangeiro a menores de quatorze (14) anos.

$\$ 3^{\circ}$. Os livros destinados ao ensino primário serão exclusivamente escritos em língua portuguesa (DELBONI, 2018).
}

A força impositiva dessa política nacionalista, que se materializou em um processo histórico de colonização cultural, étnica e linguística manifestada pela xenofobia, intolerância em relação à diversidade étnica, se mantém até os dias atuais. A recusa da importância da língua materna das crianças pomeranas, das crianças manauaras de várias etnias indígenas e tantas outras de imigração, como elemento constitutivo dessas crianças, além de ter provocado o silenciamento e a hierarquização da língua, retirou dessas crianças o direito mais básico de qualquer ser humano, o direito de falar e agir nos espaços públicos na sua língua materna, o direito de conhecer a história ancestral, os saberes, as práticas sociais do seu grupo étnico. Enfim, passou a selecionar quem tem o direito à voz e quem deve ser silenciado.

Na nossa ótica, a subalternização desses grupos tem sido ainda mais sublinhada neste momento singular da história, em que nos deparamos com condições de excepcionalidade - isolamento social. A medida de enfrentamento à pandemia do coronavírus SARS-COV2 ${ }^{4}$ tem colocado uma lente de aumento sobre um pacote de crises (sanitárias, econômicas, políticas, ecológicas, climáticas), que já estavam em curso. Antes da pandemia e com ela, milhares de pessoas têm tido suas vidas interrompidas pelos mais diversos tipos de violências que ainda imperam no Brasil. Nesse sentido, lembramos de Miguel Otávio Santana da Silva, 5 anos, impedido pela empregadora de sua mãe de ficar junto desta, caindo do 90 andar de um edifício em Recife (PE); Ana Carolina de Souza Neves, 8 anos, morta por uma bala perdida que atingiu sua cabeça quando estava dentro de casa, em Belford Roxo (RJ). Destacamos, ainda, as crianças mortas pelo aparato estatal: na cidade do Rio de Janeiro, Kauê dos Santos, 12 anos, baleado na cabeça no Complexo Chapadão; Ágatha Félix, 8 anos, no

\footnotetext{
${ }^{4}$ Causador da doença Covid-19, oficialmente declarada como pandemia pela Organização Mundial da Saúde em $1^{\circ}$ de março de 2020.
} 
Complexo do Alemão. No mesmo estado, João Pedro, 14 anos, foi atingido pelas costas, dentro de sua própria casa, por um tiro de fuzil em operação policial, no complexo do Salgueiro, em São Gonçalo (RJ).

A violência se presentifica de forma intensa na cidade, o que não significa que populações do campo estejam livres. Pelo contrário, temos assistido a violências de todo o tipo. Destacamos o ataque a indígenas da etnia Gamela, no Maranhão, em conflito de terra com fazendeiros e atacados por pistoleiros (VIANA, 2017); o abandono, pelo governo federal, de populações indígenas durante a pandemia, o que levou à morte de nove crianças em territórios Yanomami, Waputha e Kataroa, em Roraima (TEÓFILO, 2021); o aumento do trabalho infantil, em decorrência da falta de condições de acesso de crianças pobres e do campo ao ensino remoto a partir de março de 2020, que afetou, dentre milhares de alunas/alunos de zonas rurais, adolescentes dos municípios de Nioaque e Porto Murtinho, Mato Grosso do Sul, as/os quais foram encontradas/os realizando trabalho escravo no campo (SUAREZ et al., 2021).

Esses fatos nos remetem ao trabalho literário de Saramago (2013), que, usando o recurso da metáfora, mostra em sua obra "Ensaio sobre a cegueira" o quanto toda uma sociedade, com raras exceções, vai se tornando cega e indiferente à sua realidade. As crises que, no conjunto da sociedade, parecemos não enxergar, são encampadas por características de fenômenos antigos, com os quais a espécie humana convive por milênios, como é o caso do patriarcado, e por séculos, como ocorre em relação ao colonialismo e ao capitalismo. Juntos, eles compõem um tripé que gera toda forma de dominação, exclusão e as múltiplas desigualdades diante das quais estamos na atualidade.

Do ponto de vista metodológico, apropriamo-nos do conceito de interseccionalidade, atentas às dimensões de raça/etnia, classe, gênero e idade, tendo a referência do feminismo negro, potência em movimento, que, como afirma Carla Akotirene, em Interseccionalidade (2019), ao historicizar o conceito, exalta e afirma:

\footnotetext{
A coragem de Kimberlé Crenshaw de cunhar a interseccionnalidade no âmbito do Direito, setor branco e elitista, reserva o caráter ético da mulher negra iletrada que leva o celular escondido na vagina para atender o filho preso. (...) Certamente o Atlântico gera maresia feminista durante a travessia interseccional. Longe de ser fragmentada, liberal e cisheterossexista, a inteseccionalidade é dimensão prática, precisamos do horizonte enquanto os navios estão atravessando, mas a fome de justiça depende da vida garantida agora. (AKOTIRENE, 2019, p. 112).
}

Essa perspectiva de resistência, da interseccionalidade atlântica à brasileira, reforçada por uma irreverência de desobediência sistêmica (AKOTIRENE, 2019), muito 
nos inspira para as infâncias migrantes em movimento, pois estas são permeadas por fissuras com muitas contradições (SILVA; FARIA, 2021); instigando-nos em como identificar nos documentos questões em torno da origem étnica, cultural, linguística que procura dar visibilidade à dominação e a xenofobia das crianças pomeranas, crianças manauaras de ascendência indígenas e crianças indígenas, que não estão incluídas na categoria universal, genérica de infância.

Isto posto, este artigo, resultado de uma pesquisa documental, pretende analisar as opressões étnicas, linguísticas e culturais que operam simultaneamente, situando as crianças pomeranas e manauaras em condições de desigualdades, problematizando os documentos que orientam as políticas públicas para a Educação Infantil.

\section{DIVERSIDADE LINGUÍSTICA NOS DOCUMENTOS QUE ORIENTAM AS POLÍTICAS PÚBLICAS DA EDUCAÇÃO INFANTIL SOB O OLHAR DECOLONIAL}

Lançar um olhar decolonial aos documentos que orientam as políticas públicas da Educação Infantil e identificar o protagonismo das crianças pomeranas, manauaras e tantas outras crianças que foram "acidentadas" 5 pela história, sejam aquelas das crianças indígenas, afro-brasileiras, quilombolas, ribeirinhas, ciganas, faxinenses (que plantam mate e criam porco), de comunidades de "fundo de pasto", geraizeiros (habitantes do sertão), pantaneiras, caiçaras (pescadoras do mar), seringueiras, castanheiras, quebradeiras de coco de babaçu, de povos atingidos por barragem, comunidades de terreiro e, elucidar as diversas formas de resistência ao projeto colonizador europeu como a única legítima e possível é o nosso grande desafio.

Orientado pela Constituição Federal e em atendimento às determinações da Lei de Diretrizes e Bases da Educação Nacional (Lei 9394/96), que estabelece pela primeira vez na história de nosso país que a Educação Infantil é a primeira etapa da Educação Básica, na década de 90, o Ministério da Educação (MEC) realizou vários seminários e debates, com a participação de diferentes segmentos e organizações sociais, que resultou em uma série de publicações, buscando contribuir para delineamento de políticas públicas, formação de professores, práticas pedagógicas, elaboração de propostas pedagógicas e currículo da Educação Infantil. Tais documentos são: Referenciais Curriculares Nacionais (RCNEI, 1998); Documento Política Nacional de Educação Infantil: pelo direito das crianças de zero a seis anos à Educação (2006); Parâmetros Nacionais de Qualidade para a Educação Infantil- V I e II (2006); Critérios

\footnotetext{
5 Termo utilizado por Carla Akotirene (2019).
} 
para um atendimento em creches que respeite os direitos fundamentais das crianças (2009); Indicadores de Qualidade na Educação Infantil (2009); Diretrizes Curriculares Nacionais para a Educação Infantil (2010); Plano Nacional de Educação (PNE- 20142024); Base Nacional Comum Curricular - Educação Infantil (2017).

O Referencial Curricular Nacional para a Educação Infantil (RCNEI), pulveriza em seus três volumes a discussão da diversidade cultural. Reforça o direito ao reconhecimento das crianças em suas diferenças culturais e étnicas destaca a importância da inserção das crianças em atividades diversificadas e práticas sociais, sem discriminação. Recomenda o respeito e o conhecimento de algumas manifestações culturais e a valorização das singularidades das crianças na organização do trabalho pedagógico como fator de enriquecimento pessoal e cultural. O documento nos convoca a olhar no interior das instituições de educação infantil a pluralidade cultural, ou seja, a diversidade étnica, as crenças, os valores de nossa sociedade. O trabalho com a diversidade e a convivência com a diferença são destacados no RCNEI como possibilidade de ampliação de novos horizontes para adultos e crianças (BRASIL, $\left.1998^{a}\right)$.

Em seu terceiro volume, no entanto, a temática da "diversidade" aparece de forma bem mais explícita no eixo do trabalho "Natureza e Sociedade". Nele são destacadas sugestões de práticas cotidianas com as crianças pequenas, como: contação de história, realização de brincadeiras, jogos e canções que digam respeito às tradições culturais de sua comunidade e de outros grupos; o conhecimento de modos de ser, viver e trabalhar de alguns grupos sociais do presente e do passado; a identificação de alguns papéis sociais e interesse por conhecer diferentes formas de expressão cultural.

A garantia de espaços físicos, equipamentos, brinquedos e materiais adequados nas instituições de Educação Infantil, considerando as necessidades educacionais especiais e a diversidade cultural, é destacado no documento Política Nacional de Educação Infantil: pelo direito das crianças de zero a seis anos à Educação, publicado em 2005.

O Documento Parâmetros Nacionais de Qualidade para a Educação Infantil, lançado em dois volumes, no ano de 2006, chama a atenção para o respeito à diversidade cultural e étnica. Reforça a importância de se considerar as realidades locais e as diferenças de tradição. Dentre os princípios que devem orientar as propostas pedagógicas da Educação Infantil ressalta, no princípio estético, a importância da formação da criança para o "exercício progressivo da diversidade de manifestações artísticas e culturais". Apresenta ações que devem explicitar o reconhecimento da 
importância da identidade pessoal das crianças, suas famílias, professores e outros profissionais: orientação contra a discriminação de gênero, etnia, opção religiosa, de indivíduos com necessidades educacionais especiais ou diante de composições familiares diversas e estilos de vida diversificados; Explicitar nas propostas pedagógicas orientações de práticas que respeitem e valorizem a diversidade de histórias, costumes, cultura local e regional. Pela primeira vez aparece a proposta de uma educação bilingue e intercultural em um documento da educação infantil. No entanto, esse direito é assegurado às comunidades indígenas e às fronteiriças, deixando a pluralidade de infâncias sem a garantia desse direito.

No Documento em formato de cartilha, "Critérios para um atendimento em creches que respeita os direitos fundamentais das crianças", lançado em 1995, as Professoras Maria Malta Campos e Fúlvia Rosemberg levantam questões relativas à diversidade cultural das crianças. Na primeira parte do documento, Maria Malta Campos apresenta "o direito das crianças a desenvolver sua identidade cultural, racial e religiosa", dentre outros aspectos que devem ser incluídos nas práticas pedagógicas, destaca o direito das crianças negras e brancas a respeitar e gostar de seu próprio corpo e de sua aparência; a respeitarem as crenças e os costumes religiosos os mais diversos, bem como a expressão cultural das crianças, das famílias e da comunidade, e a participarem de comemorações e festas tradicionais da cultura brasileira, como carnaval, festas juninas, natal, datas especiais de nossa história. Na segunda parte do referido documento, dentre os critérios para definição de políticas e programas de creche, Fúlvia Rosemberg chama a atenção para a importância dessas políticas em procurar responder ao princípio de igualdade de oportunidade para as classes sociais, os sexos, as raças e os credos.

O Documento Indicadores de Qualidade na Educação Infantil, publicado em 2009, reconhece as identidades de meninas e meninos negras/os, indígenas e brancas e busca a valorização e a cooperação entre as crianças nas suas diferenças étnicas, raciais e culturais. Busca avaliar se a instituição disponibiliza materiais e oportunidades variadas (histórias orais, brinquedos, móbiles, fotografias - inclusive das crianças, livros, revistas, cartazes, etc.) que contemplem meninas e meninos, brancas/os, negras/os, indígenas e pessoas com deficiências.

O Documento das Diretrizes Curriculares Nacionais para a Educação Infantil, recomenda que as propostas pedagógicas das instituições de Educação Infantil deverão prever condições para o trabalho coletivo e para a organização de materiais, espaços e tempos que assegurem, dentre outras proposições, "a apropriação pelas crianças das 
contribuições histórico-culturais dos povos indígenas, afrodescendentes, asiáticos, europeus e de outros países da América, e o reconhecimento, a valorização, o respeito e a interação das crianças com as histórias e as culturas africanas, afro-brasileiras, bem como o combate ao racismo e à discriminação", conforme expressos ainda no artigo 80, em seus incisos VIII e XIX. Apresenta um tratamento diferenciado às crianças indígenas, garantindo a elas, conforme expresso no parágrafo segundo do mesmo artigo, a garantia da "autonomia dos povos indígenas na escolha dos modos de educação de suas crianças de 0 a 5 anos de idade, as propostas pedagógicas para os povos que optarem pela Educação Infantil". Para tanto, essas propostas pedagógicas devem:

I - proporcionar uma relação viva com os conhecimentos, crenças, valores, concepções de mundo e as memórias de seu povo;

II - reafirmar a identidade étnica e a língua materna como elementos de constituição das crianças;

III - dar continuidade à educação tradicional oferecida na família e articular-se às práticas socioculturais de educação e cuidado coletivos da comunidade;

IV - adequar calendário, agrupamentos etários e organização de tempos, atividades e ambientes de modo a atender as demandas de cada povo indígena.

As crianças filhas de agricultores familiares, extrativistas, pescadores artesanais, ribeirinhos, assentados e acampados da reforma agrária, quilombolas, caiçaras, povos da floresta aparecem pela primeira vez em um documento oficial em âmbito federal. A elas, conforme assegurado no artigo terceiro ainda do artigo oitavo do mesmo documento, as propostas pedagógicas da Educação Infantil devem:

\footnotetext{
I - reconhecer os modos próprios de vida no campo como fundamentais para a constituição da identidade das crianças moradoras em territórios rurais; II - ter vinculação inerente à realidade dessas populações, suas culturas, tradições e identidades, assim como a práticas ambientalmente sustentáveis; III - flexibilizar, se necessário, calendário, rotinas e atividades respeitando as diferenças quanto à atividade econômica dessas populações;

IV - valorizar e evidenciar os saberes e o papel dessas populações na produção de conhecimentos sobre o mundo e sobre o ambiente natural;

$\mathrm{V}$ - prever a oferta de brinquedos e equipamentos que respeitem as características ambientais e socioculturais da comunidade.
}

No que se refere às práticas pedagógicas que compõem a proposta pedagógica da Educação Infantil, que têm como seus eixos orientadores as interações e brincadeiras, devem garantir experiências que "possibilitem vivências éticas e estéticas e de identidades no diálogo e reconhecimento da diversidade", e que "propiciem a interação e o conhecimento pelas crianças das manifestações e tradições culturais brasileiras" (Inciso VII e XI, art. 90). 
O Plano Nacional de Educação (PNE), aprovado pela Lei no 13.005/2014, na meta específica para a Educação Infantil para o período entre 2014 e 2024, prevê estratégias para o atendimento das populações do campo e das comunidades indígenas e quilombolas na Educação Infantil nas respectivas comunidades, sem alterar seus usos e costumes, conforme expresso abaixo:

1.10) fomentar o atendimento das populações do campo e das comunidades indígenas e quilombolas na educação infantil nas respectivas comunidades, por meio do redimensionamento da distribuição territorial da oferta, limitando a nucleação de escolas e o deslocamento de crianças, de forma a atender às especificidades dessas comunidades, garantido consulta prévia e informada.

O Documento da Base Nacional Comum Curricular (BNCC), fixado pela Resolução 02/2017, do Conselho Nacional de Educação, no que diz respeito à etapa da Educação Infantil, foi construído a partir dos princípios definidos pelas Diretrizes Curriculares Nacionais para a Educação Infantil, 2009, para referenciar a construção dos currículos dessa primeira etapa da Educação Básica, nos Estados e Municípios. Considerando que as práticas pedagógicas que compõem a proposta curricular da Educação Infantil devem ter como eixos as interações e brincadeiras, conforme expresso no artigo $9^{\circ}$ das DCNEI, a BNCC, ao trazer os direitos que devem ser assegurados às crianças, conviver, brincar, participar, explorar, expressar-se e conhecer-se, faz referência à importância de a criança ampliar o conhecimento de si e do outro, respeitar a cultura e as diferenças entre as pessoas, construir sua identidade pessoal, social e cultural, constituindo uma imagem positiva de si e de seus grupos de pertencimento em dois desses direitos: conviver e conhecer-se. Nos campos de experiências em que são definidos saberes e conhecimentos que devem compor a prática pedagógica da Educação Infantil, no tema "o eu, o outro e o nós", destaca a importância de se criar, na Educação Infantil, oportunidades para as crianças ampliarem o modo de perceber a si mesmas e ao outro, valorizarem sua identidade, respeitarem os outros e reconhecerem as diferenças que nos constituem como seres humanos.

\section{POR UMA PEDAGOGIA INTERCULTURAL CRÍTICA DECONOLIAL: ALGUMAS CONSIDERAÇÕES}

A análise empreendida até então nos permitiu inferir que a temática da "diversidade cultural" aparece de forma explícita nos documentos analisados, trazendo sugestões de propostas de atividades, estratégias metodológicas que podem fazer parte das práticas cotidianas com as crianças pequenas nas instituições de Educação Infantil. 
No entanto, em diálogo com os estudos da pesquisadora Catherine Walsh (2009;2010) e do pesquisador Tubino (2004), foi possível inferir que a concepção de diversidade cultural que permeia os textos dos documentos acima referenciados é apresentada na perspectiva da interculturalidade, compreendida sob o enfoque "relacional" e "funcional", em contraponto com a perspectiva da interculturalidade crítica, defendida por essa pensadora e por esse pensador.

Os documentos partem da premissa da importância do conhecimento da diversidade cultural do nosso país e do reconhecimento das crianças enquanto coletivos de sujeitos com culturas específicas. No entanto, adotam a perspectiva da interculturalidade relacional e funcional, limitando-se ao contato, às trocas, ao diálogo, ao respeito, às relações entre culturas, no acolhimento e aceitação do "outro" nas suas diferenças e particularidades, em que as pessoas compartilham práticas, conhecimentos, valores, tradições distintas, que podem ou não ocorrer em condições de igualdade.

Postulam a necessidade da tolerância como princípio da convivência harmoniosa entre as crianças de diferentes grupos étnicos. Tais perspectivas da interculturalidade, segundo essa autora e esse autor, escamoteiam, ocultam ou até negligenciam as estruturas sociais de poder que posicionam as crianças pomeranas, manauaras e tantas outras de grupos étnicos os mais diversos, em condições de inferioridade, de subalternização. Enfim, tais documentos não tocam nas causas das desigualdades sociais decorrentes da assimetria que caracteriza a estrutura socioeconômica, excluindo as minorias étnicas e culturais (TUBINO, 2004).

Embora reconheçam a diversidade étnico-racial da sociedade brasileira, paradoxalmente, os documentos analisados são lacunares em relação à diversidade linguística brasileira, além de serem superficiais em relação às diferenças de idade, raça/etnia, gênero, classe, religião e sexualidade. O reconhecimento da diversidade linguística, em especial no que se refere às línguas minoritárias e a atuação positiva do Estado para proteger as crianças falantes dessas línguas, não foi reconhecida nos documentos normativos que norteiam as políticas públicas de Educação Infantil em nosso país.

O problema para implementar políticas educacionais que contemple o multilinguismo, é uma realidade a ser enfrentada não somente no Brasil. No caso da Itália, país com uma diversidade linguística que lembra o caso brasileiro, Clara Silva (2005) destaca que: 
A riqueza do multilinguismo, no entanto, ainda continua a ser vivenciada nas escolas como um problema, pois as ferramentas eficazes de recepção e inclusão linguística ainda são insuficientes para gerenciar classes linguística e culturalmente heterogêneas (SILVA, 2005, apud SILVA, 2019, p. 4, tradução nossa $)^{6}$.

Nos documentos analisados, somente os Parâmetros de Qualidade da Educação Infantil, em seu volume 2, faz menção à língua. No entanto, assegura somente aos indígenas a educação bilíngue. Às comunidades fronteiriças, assegura uma educação intercultural, sem se referir às diferentes línguas faladas pelas crianças que vivem nesses contextos.

Referem-se ao mundo das crianças que falam o português e protegem somente com mais veemência as línguas maternas das crianças de minorias linguísticas indígenas, embora referindo-se apenas às crianças matriculadas no Ensino Fundamental. A construção de uma nacionalidade se materializou em um processo histórico de colonização cultural, étnica e linguística, que envolveu, de um lado, a difusão da língua portuguesa e, de outro, o silenciamento e apagamento de tantas outras línguas, dando visibilidade à já pressuposta hierarquização da língua.

Enfim, parafraseando Fanon (2008, p. 40), "[...] adotar uma língua diferente daquela da coletividade em que nasceu, representa "um deslocamento, uma clivagem". Ou melhor, "falar uma língua é assumir um mundo, uma cultura" (FANON, 2008, p.50).

Salientamos que a diversidade linguística na intersecção com a divisão sexual do trabalho é uma problemática central no processo de (des)colonização brasileira, que nos remete às questões abordadas pela intelectual, feminista negra Lélia Gonzalez, que, com seu trabalho crítico e criativo, problematizando raça, classe e gênero, escancarou o racismo à brasileira, que invisibiliza, hierarquiza e exclui sujeitas/os, saberes, epistemologias, apontando os principais desafios de um processo árduo de radical descolonização. Com "Cumé que a gente fica?", transgressor "pretuguês", da célebre epígrafe do texto Racismo e Sexismo na Cultura Brasileira (1984), a autora explicita uma batalha discursiva na formação social brasileira, com limites, contradições e possibilidades de entendimento das nossas origens, bem como das bases culturais que sustentam quem somos e como produzimos nossa cultura e nossas relações sociais, sobretudo de resistências perante a imposição de um modelo civilizatório, eurocentrado, colonizador.

\footnotetext{
6 "La ricchezza del plurilinguismo, tuttavia, continua ancora essere vissuta nella scuola come un problema, in quanto sono ancora insufficienti gli strumenti di accoglienza e di inclusione linguistica efficaci per gestire classi linguisticamente e culturalmente eterogenee."
} 
Nessa direção que esperamos contribuir para o delineamento de políticas públicas para a Educação Infantil no Brasil numa perspectiva da interculturalidade crítica, que deve ser acompanhada de uma teoria decolonial latino-americana, radicalmente contrária a essas perspectivas subjacentes nos documentos analisados, mas que possam dar pistas para práxis distintas.

Para que e por que propor um único programa de leitura e escrita na Educação Infantil num país com 274 diferentes línguas faladas?

\section{REFERÊNCIAS}

ASSUMPÇÃO, Adriana Maria; AGUIAR, Gabriela de Azevedo. "Você precisa falar português com seu filho"- desafios para o processo de inclusão de crianças imigrantes em escolas do Rio de Janeiro. Revista Iberoamericana de Educação. V. 81, p. 167$189,2019$.

AKOTIRENE, Carla. Interseccionalidade. São Paulo: Sueli Carneiro; Pólen, 2019. (Feminismos plurais).

BAHIA, Joana. O tiro da Bruxa: identidade, magia e religião entre camponeses pomeranos do Estado do Espírito Santo. 2000. 328p. 2v. Tese (Doutorado). Departamento de Programa de Pós-Graduação em Antropologia Social, Universidade Federal do Rio de Janeiro, Rio de Janeiro, 2000

BENETTI, Pablo Cesar; VAINER, Carlos Bernardo. Migrações e metrópole. Travessia, São Paulo, v. 1, n. 2, p. 5-9, set./dez. 1988.

BENJAMIN, Walter. Magia e técnica, arte e política. São Paulo: Brasiliense, 1994. (Obras escolhidas). V. 1.

BEZERRA, Cecília Braga. Distantes do Berço: impactos psicológicos da imigração na infância. Dissertação (mestrado)- Universidade Federal de Santa Catarina. Centro de Filosofia e Ciências Humanas. Programa de Pós-graduação em Psicologia, Florianópolis. 2016. Disponível: https://repositorio.ufsc.br/xmlui/handle/123456789/176662. Acesso em: 25 abr. 2021.

BRASIL. Constituição da República Federativa do Brasil de 1988. Promulgada em 5 de outubro de 1988. Brasília, 1988. Disponível em <http://www.planalto.gov.br/ccivil_03/constituicao/constituição.htm>. Acesso em: 25 abr. 2021.

BRASIL. Ministério da Educação. Lei no 9.394, de 20 de dezembro de 1996. Estabelece as diretrizes e bases da educação nacional. Brasília, 1996, Diário Oficial [da] República Federativa do Brasil, Brasília, 21 dez. 1996. Disponível em: <http://portal.mec.gov.br/seed/arquivos/pdf/tvescola/leis/lein9394.pdf>. Acesso em: 25 abr. 2021. 
BRASIL. Ministério de Educação e do Desporto. Referencial curricular nacional para educação infantil. Brasília, DF: MEC, 1998b. Disponível em: <http://portal.mec.gov.br/seb/arquivos/pdf/volume2.pdf>. Acesso em: 25 abr. 2021.

BRASIL. Ministério de Educação e do Desporto. Referencial curricular nacional para educação infantil. Brasília, DF: MEC, 1998c. Disponível em: <http://portal.mec.gov.br/seb/arquivos/pdf/volume3.pdf>. Acesso em: 25 abr. 2021.

BRASIL. Ministério de Educação e do Desporto. Política Nacional de Educação Infantil: pelo direito das crianças de zero a seis anos à educação. Brasília, DF: MEC/ Secretaria de Educação Básica/DPE/COEDI, 2005. Disponível em: < http://portal.mec.gov.br/seb/arquivos/pdf/pol_inf_eduinf.pdf>. Acesso em: 25 abr. 2021.

BRASIL. Lei no 13.005, de 25 de junho de 2014. Aprova o Plano Nacional de Educação - PNE e dá outras providências. Diário Oficial [da] República Federativa do Brasil, Brasília, 26 jun. 2014. Disponível em: <http://pne.mec.gov.br/18-planossubnacionais-de-educacao/543-plano-nacional-de-educacao-lei-n-13-005-2014>.

Acesso em: 25 abr. 2021.

BRASIL. Ministério de Educação e do Desporto. Indicadores de Qualidade na Educação Infantil. Brasília, DF: MEC/ Secretaria de Educação Básica, 2009. Disponível em: < http://portal.mec.gov.br/dmdocuments/indic_qualit_educ_infantil.pdf>. Acesso em: 25 abr. 2021.

BRASIL. Ministério da Educação e do Desporto. Conselho Nacional de Educação. Diretrizes Curriculares Nacionais para a Educação Infantil. Brasília: MEC/SEB, 2010.

em: <http://portal.mec.gov.br/index.php?option=com_docman\&view=download\&alias $=97$ 69-diretrizescurriculares-2012\&category_slug=janeiro-2012-pdf\&Itemid=30192> . Acesso em: 25 abr. 2021.

BRASIL. Ministério da Educação. Base Nacional Comum Curricular. Brasília, DF: MEC, 2017. Disponível em: <http://basenacionalcomum.mec.gov.br/ Acesso em: 25 abr. 2021.

BRASIL. Ministério da Educação. Parâmetros Nacionais de Qualidade para a Educação Infantil. Brasília, DF: MEC/ Secretaria de Educação Básica, 2006a. Disponível em:

http://portal.mec.gov.br/seb/arquivos/pdf/Educinf/eduinfparqualvol1.pdf $>$. Acesso em: 25 abr. 2021.

BRASIL. Ministério da Educação. Parâmetros Nacionais de Qualidade para a Educação Infantil. Brasília, DF: MEC/ Secretaria de Educação Básica, 2006b. Disponível em:

http://portal.mec.gov.br/seb/arquivos/pdf/Educinf/eduinfparqualvol2.pdf>. Acesso em: 25 abr. 2021.

BRASIL. IBGE. Censo demográfico. 2010. Disponível em: <https://censo2010.ibge.gov.br/>. Acesso em: 10 mar. 2021. 
CAMPOS, Maria Malta. Esta creche respeita criança: critérios para a unidade creche. In: CAMPOS, Maria Malta. ROSEMBERG, Fúlvia. Critérios para um atendimento em creches que respeite os direitos fundamentais das crianças. 6 . ed. Brasília: MEC/SEF/DPEF/COEDI, 2009.

DELBONI, Juber Helena Baldotto. A escola com classes multisseriadas: memórias na mediação fotográfica. Curitiba: Appris, 2018.

DIEGUES, Manuel Júnior. Imigração, urbanização e industrialização. Rio de Janeiro: Centro Brasileiro de Pesquisas Educacionais, 1964.

DEMARTINI, Zeila de B. Relatos orais, imigração e infância. III ENCONTRO ANUAL DA ANPOCS. Caxambu/MG, 2006 (mimeo).

FANON, Frantz. Pele Negra, Máscaras Brancas. Salvador: Edufba, 2008.

FERNANDES, Bernardo Mançano; CERIOLI; Paulo Ricardo.; CALDART, Roseli Salete. Primeira Conferência Nacional "Por Uma Educação Básica do Campo", Petrópolis, RJ: Vozes, 2004.

GARCIA, Cecília. Infância e diáspora: como sente - e como a escola pode receber uma criança imigrante? 2015. Portal Aprendiz. Disponível em https://portal.aprendiz.uol.com.br/2015/12/18/infancia-e-diaspora-como-se-sente-ecomo-escola-pode-receber-uma-crianca-imigrante/ Acesso em: 25 abr. 2021.

GOES, José Roberto de; FLORENTINO, Manolo. Crianças escravas, crianças dos escravos. In: PRIORE, Mary Del. História das crianças no Brasil. 6. ed. São Paulo: Contexto,2007. p. 177-191.

GONZALEZ, Lélia. Racismo e sexismo na cultura brasileira. Revista Ciências Sociais Hoje, Anpocs, p. 223-244, 1984.

HIRATA, Helena; KERGOAT, Danièle. Novas configurações da divisão sexual do trabalho. Cadernos de Pesquisa [online]. 2009, v.37, n.132, p. 595-609.

KOHCRAUSCH, Simone. A Educação Infantil em Nova Hartz: de sua origem a novas possibilidades. Universidade do Vale do Rio dos Sinos.2006. Dissertação (Mestrado)Programa de Pós-graduação em Educação, Universidade do Vale do Rio Dos Sinos, São Leopoldo, 2006.

KRENAK, Ailton. Ideias para adiar o fim do mundo. Rio de Janeiro: Companhia das Letras, 2019.

MAHER, Terezinha de Jesus Machado. A criança indígena do falar materno ao falar emprestado. In: FARIA, Ana Lúcia Goulart de; MELLO, Suely Amaral (Orgs.). 0 mundo da escrita no universo da pequena infância. (Col. Polêmicas do Nosso Tempo). São Paulo: Autores Associados, 2005. p.75-108.

MAHER, Terezinha Machado. Definições de infância na Amazônia ocidental indígena: a perspectiva local e o etnocentrismo. Leitura: Teoria \& Prática, Campinas, v.31, n.61, p.237-254, nov. 2013. 
MAHER, Terezinha. Do casulo ao movimento: a suspensão das certezas na educação bilíngue e intercultural. In: Stella Maris Bortoni-Ricardo Cavalcanti. Marilda. C. (Orgs.). Transculturalidade, linguagem e educação. Campinas: Mercado de Letras, 2007. p. 67-96.

MARTINS, Jose de Souza. Regimar e seus amigos- A criança na luta pela terra e pela vida. In: O Massacre dos inocentes - a criança sem infância no Brasil. São Paulo: Hicitec, 1991. p.51- 8.

NASCIMENTO, Maria Letícia. MORAIS. Carolina Grandino Pereira de. (In) visibilidade das crianças imigrantes na cidade de São Paulo: questões para pensar a cidadania da pequena infância. V.27. n.2. Revista Espaço Pedagógico[online].Passo Fundo, p.437-458. Maio/Ago. 2019. Disponível em: www.ufp.br/seer/index.php/rep.Espaço Pedagógico. Acesso em: 13 mar. 2021.

RATUSNIAK, Célia; MAFRA, Ivanilde dos Santos; SILVA, Vanderlete Pereira. A travessia das infâncias no Amazonas no contexto de distanciamento social. Revista Zero-a-Seis, Florianópolis, v. 22, n. especial, p. 1364-1382, dez./ dez. 2020.

ROSEMBERG. Fúlvia. A política de creche respeita criança: critérios para políticas e programas de creche. In: CAMPOS, Maria Malta; ROSEMBERG, Fúlvia. Critérios para um atendimento em creches que respeite os direitos fundamentais das crianças. 6.ed. Brasília: MEC/SEF/DPEF/COEDI, 2009. 44p. p. 21.

SARAMAGO, J. Ensaio sobre a cegueira. 19. ed. São Paulo: Cia. das Letras, 2013.

SILLER, Rosali Rauta. A construção da subjetividade no cotidiano da educação infantil. 1999. 214p. Dissertação (Mestrado em Educação). Programa de PósGraduação em Educação, da Universidade Federal do Espírito Santo. 1999.

SILLER, Rosali Rauta. DIVERSIDADE LINGUÍSTICO-CULTURAL: O DIREITO DAS CRIANÇAS POMERANAS À DIFERENÇA. In: VII Congresso Paulista de Educação Infantil/ IV Simpósio Internacional de Educação Infantil, 2020, São Paulo. Anais [...], 2020, p. $1-2$.

SILLER, Rosali Rauta. Infância, educação infantil, migrações. 2011. 261p. Tese (Doutorado em Educação) - Programa de Pós-Graduação em Educação, Faculdade de Educação da Universidade Estadual de Campinas, Campinas, 2011.

SILVA, Adriana A.; FARIA, Ana Lúcia Goulart de. Da Comédia Infantil: entrelaçando gêneros, classes, raças e infâncias estrangeiras. Revista Zero-a-Seis, Florianópolis, v. 23, n. 43, p. 444-470, jan./jun., 2021.

SILVA, Clara. Insegnare e apprendere la lingua seconda nel contesto migratorio. Il caso dell'Italia. Educação. Santa Maria. v. 44. 2019 Disponível em: https://periodicos.ufsm.br/reveducacao. Acesso em: 19 mai. de 2021.

SILVA, Vanderlete Pereira. Diversidade cultural e resistência: as mulheres manauaras e a educação das crianças pequenininhas. In: Pesquisas e Pedagogias: Educação para as diferenças. Barreiro, Alex; Cavalcante, Nélia Aparecida da Silva; Faria, Ana Lúcia Goulart de (Orgs.). Uberlândia: Navegando Publicações, 2020, pp 221-240. 
SPIVAK, Gayatri Chakravorty. Pode o subalterno falar? Trad. Sandra Regina Goulart Almeida; Marcos Pereira Feitosa; André Pereira. Belo Horizonte: Editora da UFMG, 2010.

SUAREZ, Joana et al. Sem escola, sem recreio, sem futuro. Repórter Brasil, 22 mar. 2021. Disponível em: <https://reporterbrasil.org.br/2021/03/sem-escola-sem-recreiosem-futuro/>. Acesso em: 10 abr. 2021.

TEÓFILO, Sarah. Yanomamis denunciam morte de nove crianças indígenas com suspeita de covid-19. Correio Brasiliense, 28 jan. 2021. Disponível em: <https://www.correiobraziliense.com.br/brasil/2021/01/4903250-yanomamisdenunciam-morte-de-nove-criancas-indigenas-com-suspeita-de-covid-19.html>. Acesso em: 10 abr. 2021.

TRESSMANN, Ismael. Da sala de estar à sala de baile: estudo etnolinguístico de comunidades camponesas pomeranas do Estado do Espírito Santo. Tese de Doutorado em Linguística. Programa de Pós-Graduação em Linguística, Universidade Federal do Rio de Janeiro, 2005.

TUBINO, Fidel. Del interculturalismo funcional al interculturalismo crítico. Lima: PUC-pe, 2004.2 Disponível em: http:www.pucp.edu.pe/invest/ridei/pdfs/inter_funcional.pdf. 2004. Acesso em: 01 abr. 2021.

TURRA, Maria de Lourdes. Escola, homogeneidade e diversidade cultural. In: GONÇALVES, Maria Alice Resende (org.). Educação e Cultura: pensando em cidadania. Rio de Janeiro: Quartet, 1999.

VAINER, Carlos Bernardo. Estado e migrações no Brasil. Anotações para uma história das políticas migratórias. Travessia: revista do imigrante. Publicação do CEM. Ano XIII, n.36, jan-abr, p.15-3, 2000.

VIANA, Talita Bedinelli. A luta por terras e pelo resgate da memória dos gamela, apagada desde o Brasil colônia. El País Brasil, 7 maio 2021. Disponível em: <https://brasil.elpais.com/brasil/2017/05/06/politica/1494107739_378228.html>. Acesso em: 10 abr. 2021.

WALSH, Catherine. Interculturalidade crítica e educação intercultura. Exposição apresentada no Seminario "Interculturalidad y Educación Intercultural", organizado pelo Instituto Internacional de Integración del Convenio Andrés Bello, La Paz, 9-11 de marzo de 2009.

WALSH, Catherine. Interculturalidad crítica y educación intercultural. In: VIAÑA, Jorge., Tapia, Luis; WALSH, Catherine. (Eds.). Construyendo Interculturalidad Crítica. La Paz: Instituto Internacional de Integración, 2010. p. 75-96. 


\section{NOTAS}

TÍTULO DA OBRA

DIVISÃO SEXUAL DO TRABALHO E DIVERSIDADE LINGUÍSTICA NA SUBALTERNIZAÇÃO DAS INFÂNCIAS: OPRESSÕES ÉTNICAS, LINGUÍSTICAS E CULTURAIS NA REPRODUÇÃO DAS

\section{DESIGUALDADES}

Sexual division of labor and linguistic diversity in the subalternization of childhoods: ethnic, linguistic and cultural oppressions in the reproduction of inequalities

Adriana Alves da Silva

Doutora em Educação

Docente colaboradora da Universidade do Estado de Santa Catarina-Udesc

Florianopolis, Brasil

silvadida07@gmail.com

Ohttps://orcid.org/0000-0002-1407-783X

Rosali Rauta Siller

Doutorado em Educação

Professora da Universidade Federal do Espírito Santo Departamento de Teorias de Ensino e Práticas Educacionais do Centro de Educação Vitória-ES, Brasil

rauta13@gmail.com

Ohttps://orcid.org/0000-0002-5296-8908

Vanderlete Pereira da Silva

Mestra em Educação

Professora titular da Universidade do Estado do Amazonas

Escola Normal Superior

Manaus-AM, Brasil

vpsilva@uea.edu.br

- $\underline{\text { https://orcid.org/0000-0001-9353-3110 }}$

Endereço de correspondência do principal autor

Av. Madre Benvenuta, 2007. Itacorubi, CEP 88.035-901, Florianópolis, SC, Brasil.

\section{AGRADECIMENTOS}

Não se aplica.

\section{CONTRIBUIÇÃO DE AUTORIA}

Concepção e elaboração do manuscrito: A.A. Silva; R.R. Siller; V.P. Silva

Coleta de dados: A.A. Silva; R.R. Siller; V.P. Silva

Análise de dados: A.A. Silva; R.R. Siller; V.P. Silva

Discussão dos resultados: A.A. Silva; R.R. Siller; V.P. Silva

Revisão e aprovação: A.A. Silva; R.R. Siller; V.P. Silva

\section{CONJUNTO DE DADOS DE PESQUISA}

Todo o conjunto de dados que dá suporte aos resultados deste estudo foi publicado no próprio artigo.

\section{FINANCIAMENTO}

Não se aplica.

\section{CONSENTIMENTO DE USO DE IMAGEM}

Não se aplica.

\section{APROVAÇÃo de COMITÊ dE ÉTICA EM PESQUISA}

Não se aplica.

\section{CONFLITO DE INTERESSES}

Não se aplica. 
LICENÇA DE USO - uso exclusivo da revista

Os autores cedem à Zero-a-Seis os direitos exclusivos de primeira publicação, com o trabalho simultaneamente licenciado sob a Licença Creative Commons Attribution (CC BY) 4.0 International. Esta licença permite que terceiros remixem, adaptem e criem a partir do trabalho publicado, atribuindo o devido crédito de autoria e publicação inicial neste periódico. Os autores têm autorização para assumir contratos adicionais separadamente, para distribuição não exclusiva da versão do trabalho publicada neste periódico (ex.: publicar em repositório institucional, em site pessoal, publicar uma tradução, ou como capítulo de livro), com reconhecimento de autoria e publicação inicial neste periódico.

PUBLISHER - uso exclusivo da revista

Universidade Federal de Santa Catarina. Núcleo de Estudos e Pesquisas da Educação na Pequena Infância - NUPEIN/CED/UFSC. Publicação no Portal de Periódicos UFSC. As ideias expressadas neste artigo são de responsabilidade de seus autores, não representando, necessariamente, a opinião dos editores ou da universidade.

EDITORES - uso exclusivo da revista Márcia Buss-Simão e Kátia Agostinho.

HISTÓRICO - uso exclusivo da revista

Recebido em: 03-05-2021 - Aprovado em: 18-06-2021 